\author{
Editorial
}

\title{
Symposium issue
}

It is with great pleasure that I introduce in this issue of the Journal of Vocational Rehabilitation a selection of the proceedings from the May 1995 International Symposium on Supported Employment that was held in Norfolk, Virginia. This symposium had been predominantly a national conference until 1995, when it was significantly broadened to include over 700 participants with approximately 80 of these individuals representing 20 foreign countries. The program was delivered over a 3-day period and numerous papers were presented in the supported employment area. What Michael Barcus and Valerie Brooke have done in this issue is to provide crucial editorial leadership design, and support of some of the better papers that emerged from this conference. It is noteworthy that in this Symposium, as well as previous ones that we have held at the Rehabilitation Research and Training Center on Supported Employment at Virginia Commonwealth University since 1983, that the focus is on applied practices for direct service of job coaching in business and industry. The focus is also firmly directed toward assisting those people with the most severe disabilities to achieve the goals that they seek.

As can be seen in this issue, we have identified an important array of different topics and not exclusively in supported employment. There is information on recreation, transition from school to adulthood, working with business, and other program information that will help the direct service provider and managers in the program decision making process.

Supported employment has grown from a small university-based program in the late 1970s into a global entity in the rehabilitation arena. At one time supported employment was nothing more than a few isolated demonstration programs, although it is hard to believe that this was less than 15 years ago. Today in the United States there are well over 100000 people participating in supported employment and at least another 25-50 thousand throughout countries such as England Ireland, Netherlands, Japan, Hong Kong, Germany, Spain, Portugal, Canada and Australia. Supported employment has clearly become the desirable alternative to segregated day program activities that usually result in no pay, no integration, and little or no advancement into a true career path. While supported employment continues to have some detractors and is not the perfect model for every individual with a disability, it certainly is a highly valuable alternative for the hundreds of thousands of people in the world that continue to be segregated off in large disability centers. Surely as we close out the twentieth century, all of us in the disability field must ask the question: Are center-based service programs what people with disabilities want or need? Why not try a supported employment or competitive employment approach first before downgrading to a more segregated alternative? Why not give the 
person with the disability a full choice in the partnership of selecting a job and help him or her shoot for a higher level of aspiration than an adult activity center or sheltered workshop?

The conference that took place in May of 1995, as well as one that has just recently finished on October 19-21 in Dublin, Ireland, that is, the European Union on Supported Employment, were both major meetings to bring together leading advocates in the world on supported employment. This issue represents an effort at sharing some of the proceeding from the Norfolk, Virginia (USA) conference, and we would hope to provide additional publication of other symposium proceedings in the future.

The challenge is in front of all of us, but especially families of persons with disabilities, as well as individuals themselves. As there has been an increasing move away from professional control and as the individual with a disability increasingly asserts his or her own rightful roles and responsibilities, there will be a necessity for greater amounts of advocacy and efforts at accessing competitive employment opportunities. In order for an individual with disabilities to engage in full self determination of their fate, there is a need to not only have the information, but the courage to challenge the establishment which may find it easier to maintain the status quo of people with disabilities being maintained in segregated day programs. Persons with disabilities and their families must take a leadership role in challenging this bureaucratic establishment. 